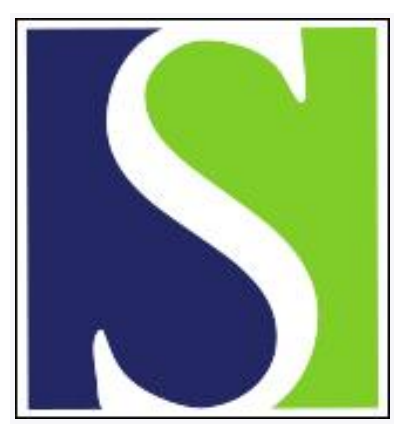

Scand J Work Environ Health 2003;29(5):329-336

https://doi.org/10.5271/sjweh.739

Issue date: Oct 2003

\title{
Relationship between silicosis and smoking
}

by Hessel PA, Gamble JF, Nicolich M

Key terms: amorphous silica dust; cigarette; occupational lung disease; review; silicosis; smoking

This article in PubMed: www.ncbi.nlm.nih.gov/pubmed/14584513

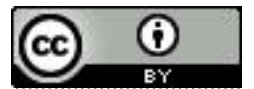




\title{
Relationship between silicosis and smoking
}

\author{
by Patrick A Hessel, PhD, ${ }^{1}$ John FGamble, PhD, ${ }^{2}$ Mark Nicolich, $P h D^{2}$
}

\begin{abstract}
Hessel PA, Gamble JF, Nicolich M. Relationship between silicosis and smoking. Scand J Work Environ Health 2003;29(5):329-336.

An evaluation of the relationship between silicosis and smoking is important in exploring the etiology of silicosis, and the relationship could have an impact on studies dealing with silicosis and lung cancer. Data addressing this relationship were found in studies designed explicitly to evaluate this association and studies that explored other questions. Studies based on compensation registers were excluded. Smoking data and methods varied across the studies considered. Of the13 studies, 3 supported the hypothesis that smoking was positively associated with silicosis, 8 provided limited support (most included subpopulations showing positive associations), and 1 did not support the hypothesis. The only autopsy study suggested an inverse association. It is unclear whether the generally positive results indicate that smoking predisposes to silicosis or that nonspecific radiographic appearances from smoking were interpreted as silicosis in some studies. A positive association between radiographic silicosis and smoking would bias studies of silicosis and lung cancer, especially those lacking smoking data.
\end{abstract}

Key terms cigarettes, occupational lung disease, review, silica dust.

It has been suggested that smoking causes radiographic opacities similar to those resulting from the inhalation of inorganic dust $(1,2)$. Some authors have acknowledged a relationship between smoking and radiographic opacities of low profusion, but they do not believe that smoking independently produces opacities that are indistinguishable from pneumoconiosis (3-6).

Smoking is related to several factors that are associated with silicosis in some studies (eg, emphysema, reduced lung function, respiratory symptoms, and lung cancer). As such, clarifying the relationship between smoking and silicosis is important in discerning the impact of silicosis per se on respiratory morbidity and mortality.

Plausible mechanisms can be proposed for both positive and negative associations between silicosis and smoking. The inhibition of mucociliary clearance by cigarette smoke may result in enhanced retention of silica and increased risk of silicosis (7). In addition, smoking may increase bronchovascular fibrosis and emphysema, both of which could create radiographic shadows misinterpreted as silicosis, although these mechanisms are usually associated with the production of small, irregular opacities (8). Alternatively, the increased production of bronchial mucus and airway narrowing resulting from smoking could increase turbulent flow in the airways and enhance the interception of silica particles in the proximal airways, resulting in enhanced mucociliary clearance $(9,10)$. Although the studies reviewed in this paper have addressed the relationship between silicosis and smoking, the relative contributions (if any) of the suggested mechanisms could not be evaluated.

Blanc \& Gamsu (6) suggested that the classification system of the International Labour Organization (ILO) (11) is the keystone to evaluating the relationship between smoking and silicosis because it standardizes the assessment of severity, allows comparison between studies, and discriminates between opacities consistent

1 University of Alberta, Edmonton, Alberta, Canada.

2 Exxonmobil Biomedical Sciences, Inc, Annandale, New Jersey, United States.

Reprint requests to: Dr Patrick A Hessel, Exponent, Two North Riverside Plaza, Suite 1400, Chicago, IL 60606, USA. [E-mail: phessel@exponent.com] 
with silicosis (rounded opacities) and small irregular opacities commonly associated with, for example, asbestosis. Some studies have shown that radiological opacities from cigarette smoking (in the absence of fibrous dust exposure) can be distinguished from small irregular opacities consistent with pneumoconiosis (5, $12,13)$. However, there is an association between smoking and the radiographic appearance of small irregular opacities among workers exposed to asbestos.

Some studies have examined the relationship between smoking and silicosis explicitly, usually using multivariate methods to control for potentially confounding factors and evaluating smoking status (eg, current smoker, ex-smoker, or nonsmoker) or pack-years of smoking. The relationships were usually characterized by series of odds ratios (OR). In these studies, biological gradients were assessed by examining trends in the odds ratios for smoking (or pack-years) by grade of silicosis.

In other studies the relationship between silicosis and smoking was an incidental finding. In these investigations, the prevalence of smoking (sometimes packyears) was tabulated by category of silicosis. These studies often did not include statistical adjustment for potentially important differences between categories of silicosis, and their utility was therefore limited. In these studies, the relationship between silicosis and smoking was evaluated by comparing the prevalence of smoking (usually current smokers plus ex-smokers) for each category of silicosis or by calculating prevalence rate ratios by radiographic category.

Most studies defined silicosis as being present if the profusion of opacities was ILO category 1/0 or greater. Some included category $0 / 1$ as silicosis, possibly because of small numbers of subjects above this level. However, the instructions for the ILO classification state that category $0 / 1$ is used to describe an X-ray for which major category 1 (ie, silicosis) was seriously considered, but which was concluded not to represent silicosis. Some studies included both small rounded and small irregular opacities as representing silicosis in workers who were occupationally exposed to silica. Others included only small rounded opacities as representing silicosis. Small irregular opacities of low profusion are, in fact, associated with several factors, including age, cigarette smoking, radiographic technique, obesity, and various dusts in the workplace (eg, asbestos, diatomaceous earth, coal, kaolin, and bauxite) (14). Computed tomography has been used in some studies to supplement chest X-rays and categories have been created from both the X-rays and computed tomographic results.

For relevant studies, a Medline search was conducted, identifying studies written in English that assessed relationships between lung function, silicosis, smoking, and dust exposure. The reference lists of all the studies were reviewed, and additional studies were identified. In the summaries that follow, the studies have been evaluated and characterized by the extent to which they support or refute the initial hypothesis (ie, that smoking is positively related to silicosis), the consistency of the evidence, the strength of the association, and the biological gradient being considered.

\section{Cross-sectional studies of active workers}

Irwig \& Rocks (15) conducted a cross-sectional study of 1973 white South African gold miners who were employed from 1968 to 1971 and were between 45 and 54 years of age, began working in the gold mines from 1936 to 1943 , and had worked for at least 10 years underground. X-rays were read blindly by a single reader using the ILO U/C classification (16). There were 134 (7\%) with radiographic silicosis: $69(3.5 \%)$ in category $1,43(2.2 \%)$ in category 2 , and $22(1.1 \%)$ in category $\geq 3$. Smoking histories were available for 1830 miners. When compared with nonsmokers, ex-smokers and current smokers had odds ratios and $95 \%$ confidence intervals $(95 \% \mathrm{CI})$ of $1.4(95 \% \mathrm{CI} 0.7-2.7)$ and $1.2(95 \% \mathrm{CI}$ 0.7-2.2), respectively, for silicosis and smoking. The study provided limited support for the smoking-silicosis hypothesis.

Cowie \& Mabena (17) studied all black gold miners employed underground with radiographic silicosis diagnosed during a routine surveillance program. For every five silicotics, two nonsilicotics were matched by age and day of X-ray. Smoking and occupational histories were obtained by questionnaire, and full-size chest radiographs were taken (the initial X-rays were miniatures). Jobs were divided into three categories based on the intensity of respirable dust and physical demands. Of the study population of 1197 men, $28 \%$ were in category $0,36 \%$ were in category $1,31 \%$ were in category 2 , and $4 \%$ were in category 3 .

The odds ratios for ex-smokers and current smokers relative to nonsmokers were 1.0 (95\% CI 0.8-1.4) and 1.8 (95\% CI 1.2-2.7), respectively. The percentage of ex-smokers and mean pack-years increased with increasing category of silicosis. The percentage of current smokers decreased with increasing category of silicosis, and pack-years were constant across the categories. The authors stated that a regression analysis revealed "no interaction ... between smoking and silicosis ... [p 82]". Because the emphasis of the analysis was not on the relationship between silicosis and smoking, the results of the analysis were not presented.

The data provide limited support for an association between silicosis and smoking. The percentage of never smokers did not change with increasing grade of 
silicosis. The complementary changes in the percentage of current smokers and ex-smokers with increasing grade of silicosis may indicate that workers diagnosed with silicosis were more likely to give up smoking as a result.

Swaen \& Meijers (18) conducted a cross-sectional study of 3258 Dutch ceramic workers in 158 different companies [also reported in Swaen et al (19) and Meijers et al (20)]. There were 135 workers (4.1\%) with simple silicosis radiographically. The respirable quartz concentration exceeded standards for many occupations. There was little difference in the prevalence of silicosis between the nonsmokers and moderate smokers. Among those with more than 20 years of exposure, the prevalence of silicosis among those smoking $\geq 20$ cigarettes per day was $15 \%$, compared with $11 \%$ for light smokers and $10 \%$ for nonsmokers $(\mathrm{P}<0.05$ for heavy smokers versus light and nonsmokers combined). The data for heavy smokers with at least 20 years of exposure provide limited support for the hypothesis.

To investigate the relationship between exposure and radiographic changes, Cherry et al (21) and McDonald et al (22) studied 1080 men, born in 1916-1945 and working for $\geq 10$ years prior to 1960 in the pottery industry at Stoke-on-Trent. Detailed smoking histories had been collected; however, the analysis of silicosis and smoking classified workers as ever or never smokers. The question of silicosis and smoking was not the primary aim of the study. There were 43 with X-rays in category 1,21 whose $\mathrm{X}$-rays were greater than or equal to category $2 / 1$, and 1016 with normal $\mathrm{X}$-rays. Those in category 2 had started work earlier (1936) and had had a shorter latency period ( 25 years) than those in category 1 (1942 and 34 years, respectively). The prevalence of opacities and smoking increased with cumulative exposures greater than $2 \mathrm{mg} / \mathrm{m}^{3}$-years. The prevalence of abnormal radiographs for ever smokers was about twice that of nonsmokers (OR 2.28, 95\% CI 1.02-5.10), and this difference was unlikely to be confounded by dust exposure. These data support the hypothesis.

Graham et al (23) conducted a radiographic survey of 972 granite workers ( $69 \%$ of the total workforce) in 1983 and found $2.9 \%$ with some abnormality consistent with pneumoconiosis. [Only $8(0.7 \%)$ had rounded or nodular abnormalities consistent with simple silicosis.] One of the eight abnormal radiographs with rounded opacities had a median reading of $2 / 3$ with predominantly irregular shadows. A logistic regression analysis with radiographic abnormality as the dependent variable showed statistically significant relationships with pack-years but not with smoking status. The best predictive model for an abnormal X-ray included years in granite work, pack-years, and their interaction, showing that the more years worked and the greater the number of pack-years, the greater the probability of an abnormal X-ray. The model also indicated that the effects of smoking and quartz exposure were not simply additive. The effect of quartz exposure on pneumoconiosis was stronger for light smokers than for heavy smokers. The unadjusted odds ratios, for smoking and an abnormal X-ray was 4.8 (95\% CI 1.1-44.0) for exsmokers and 2.9 (95\% CI 0.6-26.8) for current smokers.

Although the study suggests some support for the hypothesis, the fact that 20 of the 28 workers with abnormal radiographs had only irregular opacities, and all but one were smokers, limits the interpretability as it relates to silicosis specifically. The authors speculated that some irregular opacities could have resulted from chronic bronchitis or smoking.

Harber et al (24) conducted a cross-sectional survey of diatomaceous earth workers in Lompoc, California, to study the relationships between total dust (largely diatomaceous earth), cristobalite, and radiographic pneumoconiosis. Among the 492 current workers with chest $\mathrm{X}$-rays, $5 \%(\mathrm{~N}=26)$ had profusion in category $\geq 1 / 0$. Of these, 25 were ever smokers (unadjusted OR 16.7, 95\% CI 2.7-690). The opacities were primarily irregular and not predominantly in the upper zones. A multivariate analysis showed a relationship between radiographic findings and both cristobalite and total dust exposure among nonsmokers only. However, because there was only one nonsmoker with a reading above $0 / 1$, this result probably arose from differences in exposure between those with category $0 / 0$ and category $0 / 1$. The authors suggested that the radiographic abnormalities did not represent silicosis but, rather, mixed dust pneumoconiosis. Because (i) asbestos had been used at this facility, (ii) most of the opacities were irregular and not in the upper zones, and (iii) $3.5 \%$ of the X-rays showed pleural changes, it is possible that asbestosis accounted for some of the parenchymal findings, although the authors rejected that suggestion. Despite the large odds ratio for radiographic change in relation to smoking, the small number of nonsmokers with changes and the aforementioned caveats limit the study's ability to provide reliable evidence for the relationship between silicosis and smoking.

$\mathrm{Ng}$ et al (25) surveyed 218 male gemstone workers in Hong Kong, with 157 available for the analysis of radiographic category and smoking. Workers were classified into a "light exposure group" comprising cutters and carvers and referred to as "cutters" $(\mathrm{N}=47)$ and a "heavy exposure group" comprising those involved in grinding or polishing and buffing $(\mathrm{N}=110)$, referred to as "polishers". The average respirable silica exposure for the four subgroups was $60 \mu \mathrm{g} / \mathrm{m}^{3}$ for the cutters, 30 $\mu \mathrm{g} / \mathrm{m}^{3}$ for the carvers, $100 \mu \mathrm{g} / \mathrm{m}^{3}$ for the grinders and polishers, and $160 \mu \mathrm{g} / \mathrm{m}^{3}$ for the buffers. The percentage of samples exceeding the occupational exposure limit was 33, 9, 57, and 68, respectively. Buffing 
commonly involved the use of silica flour, with a quartz content often exceeding $90 \%$.

Overall, there was a positive, but nonsignificant, association between pack-years of smoking and the radiological scores $(\mathrm{P}<0.60)$. Among the cutters, 8 of 10 $(80 \%)$ with pneumoconiosis were ever smokers compared with 13 of $37(35 \%)$ of those without pneumoconiosis (OR 7.4, 95\% CI 1.2-77.9). Among the polishers, 11 of $33(33 \%)$ of those with pneumoconiosis were ever smokers compared with 30 of 77 (39\%) of those without pneumoconiosis (OR $0.8,95 \%$ CI $0.5-1.6)$. For both groups, the numbers of workers in each profusion category were too small to assess the biological gradient. The data for the cutters support the hypothesized association between silicosis and smoking, whereas the data for the more heavily exposed polishers do not. No distinction was made between rounded and irregular opacities; however, the authors noted that most of the opacities were rounded.

\section{Cross-sectional studies of active and retired workers}

Hessel et al (26) assessed the hypothesis using 4456 white gold miners with complete smoking and exposure histories and autopsies between 1976 and 1981. This group included both active and retired workers. Silicotic collagenization of the parenchyma, hilar lymph glands, and pleura was found in $42 \%, 69 \%$ and $19 \%$, respectively. A logistic regression analysis, adjusting for age and dust exposure, showed no association between ever smoking and parenchymal silicosis, a significant negative association with pleural silicosis, and no association with silicosis of the hilar glands. The odds ratios for parenchymal silicosis decreased with increasing cigarettes per day $\left(\mathrm{P}_{\text {trend }}=0.03\right)$.

The authors suggested that the data were consistent with increased mucus secretion and airway narrowing due to smoking, with more central lung deposition of dust and enhanced lymphatic clearance to the hilum among the smokers than among the nonsmokers. The data do not support the hypothesis that smoking increases the risk of parenchymal silicosis determined at autopsy and suggest that the opposite may be true.

Glover et al (27) studied 725 slate workers and exworkers and 530 men from the same area of North Wales who had never been exposed occupationally to dust. The respirable slate dust contained between 13\% and $32 \%$ quartz. The authors used the term pneumoconiosis, as they did not assume that true silicosis was being observed. Workers exposed to dusts other than slate (eg, coal, granite) were excluded; however, the authors noted disagreements regarding the shapes of the opacities (ie, rounded or irregular) between readers. The odds ratio was 1.0 (95\% CI 0.6-4.9) for ex-smokers and 0.8 (95\% CI $0.5-1.4)$ for current smokers. These data do not support the hypothesized relationship between smoking and small rounded opacities in slate workers. The authors reported a high prevalence of tuberculotic lesions, which complicated the interpretation somewhat, as there may have been some error in the opacity classification.

Ng \& Chan (28) studied 206 active and 132 previously employed granite quarry workers in Hong Kong. The potential cohort included 496 workers employed for at least 1 year between 1967 and 1985 and without silicosis. The follow-up group included 206 of the 227 (91\%) active workers, 50 of the $105(48 \%)$ workers who were transferred out of the quarries because they had silicosis (17 had died), and 82 of the 164 (50\%) who left the quarries for other reasons (36 had died).

Data were available on cumulative exposure to respirable dust and total granite dust. A multiple regression analysis of profusion of small radiological opacities found significant relationships with cumulative respirable silica and age, but not with pack-years. Data were also provided on the prevalence of smoking for those with rounded and irregular opacities (category $\geq 0 / 1$ ) and progressive massive fibrosis. The odds ratio for current smoking was 1.9 (95\% CI 0.3-14.5) for large opacities, 1.4 (95\% CI 0.7-2.7) for irregular opacities, and 1.0 (95\% CI $0.5-1.9)$ for rounded opacities. The odds ratio for ex-smoking was 5.9 (95\% CI 0.7-56.0) for large opacities, 2.9 (95\% CI 1.2-7.2) for irregular opacities, and 1.8 (95\% CI 0.6-4.9) for rounded opacities. The interpretation of the data is limited by the inclusion of those with category $0 / 1$ in the pneumoconiosis group. Despite some high odds ratios, the study provides only limited support for the hypothesis. It is not clear why there was a higher prevalence of irregular opacities (25\%) than rounded opacities (19\%), when the predominant exposure was thought to be quartz.

Wang \& Yano (29) studied 220 current and retired workers with $\geq 3$ years of exposure to silica sand containing more than $80 \%$ quartz in a refractory brick plant. Data on smoking by radiographic category were available for the 114 active workers, 6 of whom (5\%) had silicosis, and 106 workers who had retired because of silicosis. In this industry a worker was expected to retire or withdraw from a dusty job when diagnosed with pneumoconiosis. Workers were classified on the basis of routine, clinical X-ray readings, and therefore the readings were probably not blinded. It was stated that the most recent X-ray was reevaluated by a radiologist and "no inconsistent findings were found [p 300]". The actual methods and findings of the dual readings were not detailed. Twenty-six percent of the retired workers were not included because of other cardiopulmonary disease, old age, or sickness, and $16 \%$ of the active 
workers did not participate. The radiographs were classified using Chinese radiographic categories 0-III (roughly equivalent to ILO categories $0,1-2,3$ and progressive massive fibrosis, respectively). Only seven workers had X-rays read in category III. Workers without silicosis (active workers) were on an average of about 33 years younger, had fewer pack-years of smoking, and had 16 years of exposure compared with 20 23 years for those with silicosis. The percentage of exsmokers increased with increasing severity of silicosis. However, only $4 \%$ of those in category 0 were ex-smokers. Eighty percent of those in category 0 were current smokers, and the prevalence of current smoking decreased with increasing grade of silicosis. However, the average pack-years (all smokers) were approximately 14 for those with category I and II silicosis and 7.5 for those with categories 0 and III.

Because the investigators were not interested in studying the relationship between silicosis and smoking, only simple cross-tabulations were available. The odds ratios for the ex-smokers and smokers were, respectively, 6.5 (95\% CI1.7-29.7) and 0.7 (95\% CI 0.31.4). These unadjusted results were difficult to interpret given the large differences between those without silicosis (mostly young, active workers) and those with silicosis (mostly older, retired workers). Active smoking decreased and ex-smoking increased with increasing grade of silicosis. The data on pack-years were probably confounded by age. The results provide only limited support for the hypothesis that silicosis is related to smoking.

\section{Longitudinal studies}

Finkelstein (30) studied workers exposed to silica since 1950 and still employed in Ontario in 1979 or later. The data were obtained from the Ontario surveillance program, based on chest radiographs every 1-2 years for workers in dusty trades. The interpretations of radiographs were based on the 1930 Johannesburg Conference Report (31). Using this scheme, code 5 represents silicosis and code 4 stands for "dust effects." It is not clear whether both code 4 and code 5 were considered silicosis for this report. Therefore the interpretability of the study is limited. The main purpose of the study was the documentation of silicosis incidence rates. The rate ratio for silicosis among the ever smokers compared with the never smokers was 1.54 (95\% CI 0.9-2.6). The author suggested that it was plausible that a true difference existed, but the power of the study was low because of the small number of nonsmokers. The study provides only limited support for our hypothesis.

Cavariani et al (32) studied the incidence of silicosis between 1974 and 1991 among 2480 male workers in the ceramics industry in Italy, followed for about 8 years with annual X-rays. All had an X-ray read as $0 / 0$ at the first examination. Silicosis was defined as $\geq 1 / 1$ rounded opacities. The respirable silica concentrations ranged from 0.01 to $0.89 \mathrm{mg} / \mathrm{m}^{3}$ in the sanitary ware jobs and from 0.01 to $1.14 \mathrm{mg} / \mathrm{m}^{3}$ in crockery and pottery jobs. The average respirable dust concentration was about $2 \mathrm{mg} / \mathrm{m}^{3}$, and the quartz content was about $33 \%$. Only $4 \%$ had worked for $>20$ years and $86 \%$ for $<10$ years at the time of the first X-ray. At the beginning of the study $74 \%$ were ever smokers. Duration of exposure, type of industry, and smoking were significant risk factors for the development of silicosis. Exsmokers and current smokers were at increased risk of silicosis (RR 1.5, 95\% CI 0.9-2.7, and RR 1.8, 95\% CI $1.2-2.6$, respectively) after adjustment for industry, duration of exposure, and age at first exposure. This study supports our hypothesis.

\section{Discussion}

The studies are summarized in the table 1 . Thirteen were found that included smoking information by category of silicosis. Only one was based on autopsy data (26), one used the 1930 radiographic codes 4 (dust effects) and 5 (silicosis) (30), and one used the Chinese classification system (29). The remaining 10 used the ILO classification. Studies based on compensation registers were excluded because compensation for silicosis often requires symptoms or clinical findings or both in addition to (and sometimes without) radiographic findings.

$\mathrm{X}$-ray readings were done according to several methods, and, therefore, some studies included multiple, blinded readers while others used routine X-rays generated by surveillance activities - usually read by a single reader who was, in principle, not blinded. Some authors did not provide detail. Similarly, some authors did not state explicitly the types of opacities included, while others analyzed only rounded opacities and others mixed both rounded and irregular opacities. For some researchers, for example, Graham et al (23) and Harger et al (24), it was stated that many of the opacities were irregular and in the lower lung fields-inconsistent with the typical appearance of silicosis. Irregular opacities in the lower zones are known to be associated with asbestos exposure and are found in older smokers $(1,33)$. Because the prevalence of small opacities was low in many of the studies, the impact of smoking- or asbestos-related irregular opacities might have biased the risk estimates for smoking and "silicosis" upward.

Reporting or publication bias could have affected the available data in at least two ways. Because the 
Table 1. Summary of the studies. ( $R R=$ relative risk, $95 \% \mathrm{Cl}=95 \%$ confidence interval)

\begin{tabular}{|c|c|c|c|c|}
\hline Study design & Study population & $\begin{array}{l}\text { Sample } \\
\text { size }(\mathrm{N})\end{array}$ & Results ${ }^{a}$ & $\begin{array}{l}\text { Support of } \\
\text { hypothesis }^{\text {b }}\end{array}$ \\
\hline \multicolumn{5}{|l|}{ Cross-sectional } \\
\hline \multicolumn{5}{|l|}{ Active workers } \\
\hline Irwig \& Rocks, 1978 (15) & Gold miners & 1830 & $\begin{array}{l}\text { Ex-smoker: RR 1.4, 95\% Cl 0.7-2.7; current smoker: RR 1.2, } \\
95 \% \text { Cl 0.7-2.2 }\end{array}$ & Limited \\
\hline Cowie \& Mabena, 1991 (17) & Gold miners & 1197 & $\begin{array}{l}\text { Ex-smoker: RR 1.0, 95\% Cl 0.8-1.4; current smoker: RR 1.8, } \\
95 \% \text { Cl 1.2-2.7 }\end{array}$ & Limited \\
\hline Swaen \& Meijers, 1987 (18) & Ceramic workers & 3258 & $\begin{array}{l}\text { For } \geq 20 \text { years exposure: RR } 1.1 \text { for }<20 \text { cigarettes/day, } \\
\text { RR } 1.5 \text { for } \geq 20 \text { cigarettes/day }\end{array}$ & Limited \\
\hline Cherry et al, 1998 (21) & Pottery workers & 1080 & Ever smoker: RR 2.3, 95\% Cl 1.0-5.1 & Yes \\
\hline Graham et al, 1991 (23) & Granite workers & 972 & $\begin{array}{l}\text { Ex-smoker: RR 4.8, 95\% a 1.1-44.0'; current smoker: RR 2.9, } \\
95 \% \text { Cl 0.6-26.8 }\end{array}$ & Yes \\
\hline Harber et al, $1998(24)$ & Diatomaceous earth workers & 492 & Ever smoker: RR 16.7, 95\% Cl 2.7-690 c & Limited \\
\hline Ng et al, 1987 (25) & Gemstone workers & 157 & $\begin{array}{l}\text { Outters ever smoker: RR 7.4, 95\% C 1.2-77.9c; polishers } \\
\text { ever smoker: RR 0.8, 95\% Cl 0.5-1.6 }\end{array}$ & Limited \\
\hline \multicolumn{5}{|l|}{ Active and retired workers } \\
\hline Hessel et al, 1991 (26) & Gold miners & 4456 & $\begin{array}{l}1-14 \text { cigarettes/day: RR } 1.0,95 \% \text { Cl } 0.8-1.3 ; 15-24 \text { ciga- } \\
\text { rettes/day: RR 0.9, 95\% Cl } 0.7-1.2 ; \geq 25 \text { cigarettes/day: } \\
\text { RR } 0.8,95 \% \text { Cl } 0.6-1.0\end{array}$ & $\begin{array}{l}\text { Limited } \\
\text { negative }\end{array}$ \\
\hline Gover et al, 1980 (27) & Slate workers & 1255 & $\begin{array}{l}\text { Ex-smoker: RR 1.0, 95\% Cl 0.5-2.0; current smoker: RR 0.8, } \\
95 \% \text { Cl 0.5-1.4 }\end{array}$ & No \\
\hline Ng \& Chan, 1992 (28) & Granite workers & 338 & $\begin{array}{l}\text { Small rounded opacities: RR 1.8, 95\% Cl 0.6-4.9, for ex- } \\
\text { smokers and RR 1.0, 95\% Cl 0.5-1.9, for current smokers; } \\
\text { large opacities: RR 5.9, 95\% Cl 0.7-56.0, for ex-smokers and } \\
\text { RR 1.9, 95\% Cl 0.3-14.5, for current smokers }\end{array}$ & Limited \\
\hline Wang \& Yano, 1999 (29) & Refractory brick worker & 220 & $\begin{array}{l}\text { Ex-smoker: RR 6.5, 95\% Cl 1.7-29.7c; current smoker: RR 0.7, } \\
95 \% \text { Cl 0.3-1.4 }\end{array}$ & Limited \\
\hline \multicolumn{5}{|l|}{ Longitudinal } \\
\hline Finkelstain, 1995 (30) & Silica workers & 25113 & Ever smoker: RR 1.5, 95\% Cl 0.9-2.6 & Limited \\
\hline Cavariani et al, 1995 (32) & Ceramic workers & 2480 & $\begin{array}{l}\text { Ex-smoker: RR 1.5, 95\% Cl 0.9-2.7; current smoker: RR 1.8, } \\
\text { 95\% Cl 1.2-2.6 }\end{array}$ & Yes \\
\hline
\end{tabular}

a Relative to nonsmokers.

b Extent to which the study supports our hypothesis of a positive association between silicosis and smoking.

c Exact confidence interval.

relationship between silicosis and smoking was not the primary objective of most of the studies, there may have been less incentive or disincentive to publish the studies on the basis of the results related to silicosis and smoking. On the other hand, there would have been less incentive for investigators to report results related to silicosis and smoking if they were not remarkable. Given the mix of positive and negative results, it is not possible to speculate whether either bias operated. It is hoped that our review will stimulate additional analyses of existing data sets that were not included in our review.

Studies limited to active workers may have been affected by healthy worker selection and retention. This possibility may have occurred if those with silicosis who were smokers were more or less likely to continue working after the onset of silicosis than nonsmokers were. This potential bias should not have affected the studies that included former workers or the longitudinal studies. There were no systematic differences across study types, and therefore this phenomenon should not have substantially affected the results.
Several studies presented data for nonsmokers, ex-smokers, and current smokers, and, in these, the prevalence figures for ex-smokers and current smokers were often complementary, and, therefore, could suggest that the diagnosis of silicosis prompted some to quit smoking. Five studies used pack-years in addition to smoking prevalence, and cigarettes per day was used in two studies.

Few studies tested the smoking-silicosis hypothesis as part of the planned analysis and only prevalence rate ratios could be calculated using the raw, descriptive data. Most studies considered categories of $\geq 1 / 0$ as a single group, and therefore the ability to evaluate a biological gradient between smoking and the severity of silicosis was limited.

Overall, smoking showed a suggestive association with silicosis. The studies of Graham et al (23) and Harber et al (24) were suggestive of an association; however, the inclusion of irregular opacities limited the interpretability. Graham et al (23) stated this explicitly, whereas Harber et al (24) felt that the type 
pneumoconiosis being seen in diatomaceous earth workers differed from silicosis. The use of asbestos at the diatomaceous earth facility raises questions about their interpretation. The studies of Cavariani et al (32), Cherry et al (21), and the cutters in the study of $\mathrm{Ng}$ et al (25) demonstrated positive associations between silicosis and smoking. The results of Finkelstein (30) were suggestive, but they were complicated by uncertainty about the radiographic categories included.

There is a significant amount of literature on "smokers' lung" or "dirty lung", terms used to describe the radiographic appearance of the lungs of smokers. These descriptions have been attributed to interstitial fibrosis and inflammation of the alveolar walls (34). In an investigation using high-resolution computed tomography, Remy-Jardin et al (35) found that $27 \%$ of smokers (26 of 98), compared with $4 \%$ of ex-smokers ( 1 of 4 ), and none of 51 nonsmokers had evidence of parenchymal micronodules, primarily in the upper lung zones. Similar percentages of areas of ground-glass attenuation were also found. If some of these changes are visible on the $\mathrm{X}$-ray (ie, dirty lung), it is possible that some observers may interpret the "increased markings pattern" associated with smoking as pneumoconiotic changes. This possibility may explain the fairly strong associations between smoking and "silicosis" seen in some studies.

Corroborative evidence can be found in the work of Finkelstein (30). Using the Ontario classification (Johannesburg classification), he made a distinction between X-rays consistent with silicosis (code 5) and those displaying "dust effects" (code 4). In a comparative reading trial, it was shown that the code $5 \mathrm{X}$-rays were generally read in ILO classification $\geq 1 / 0$, whereas the code 4 X-rays generally fell into ILO category 0 (36). In another study examining lung cancer risk in relation to radiographic findings, workers with $\mathrm{X}$-rays classified as code 4 had a standardized mortality ratio of $2.99(95 \%$ CI 1.3-5.8), while those with X-rays classified as code 5 had a corresponding ratio of 1.5 (95\% CI 0.5-3.5) (37). Of those with code $4 \mathrm{X}$-rays, $93 \%$ had been smokers, compared with $87 \%$ of those with code $5 \mathrm{X}$-rays. These data suggest that the radiographic appearance characterized as "dust effects" was related to smoking and carried an excess risk of lung cancer. If these X-rays had been categorized as representing silicosis, an association between silicosis and smoking would have been reported. The fact that the only autopsy-based study demonstrated a negative trend between parenchymal silicosis and the intensity of smoking suggests that a misclassification of smoking-related radiographic changes as silicosis in smokers may have affected the results of some of the studies.

In summary, these studies generally supported the hypothesized positive association between silicosis and smoking. The data are limited primarily because most investigators were not exploring this relationship as their primary objective. On the basis of these studies it was not possible to determine whether this relationship resulted from the effects of cigarette smoke on pulmonary clearance mechanisms or if smoking-related changes were interpreted in some studies as representing silicosis. Regardless of the mechanisms, a positive association between silicosis and smoking would bias studies examining the relationship between silicosis and lung cancer, especially studies that do not include smoking data.

\section{Acknowledgments}

This review was funded by the Silica Coalition.

\section{References}

1. Weiss W. Smoking and pulmonary fibrosis. J Occup Med 1988;30:33-9.

2. Morgan WKC. Prevalence of radiographic appearance of pneumoconiosis in an unexposed blue collar population [letter]. Am Rev Respir Dis 1985;132:1139.

3. Kilburn KH. Classification of data on the etiologic role of cigarette smoking in pulmonary fibrosis [letter]. Am J Ind Med 1984;5:420.

4. Kilburn KH, Lilis R, Anderson HA, Miller A, Warshaw RH. Interaction of asbestos, age, and cigarette smoking in producing radiographic evidence of diffuse pulmonary fibrosis. Am J Med 1986;80:377-81.

5. Castellan RM, Sanderson WT, Petersen MR. Prevalence of radiographic appearance of pneumoconiosis in an unexposed blue collar population. Am Rev Respir Dis 1985;131:684-6.

6. Blanc PD, Gamsu G. Cigarette smoking and pneumoconiosis: structuring the debate. Am J Ind Med 1989;16:1-4.

7. Cohen D, Arai SF, Brain JD. Smoking impairs long-term dust clearance from the lung. Science 1979;204:514-7.

8. Weiss W. Cigarette smoke, asbestos, and small irregular opacities. Am Rev Respir Dis 1984;130:293-301.

9. Gough J. Emphysema in relation to occupation. Ind Med Surg 1960;29:283-5.

10. Chamberlain MJ, Morgan WKC, Vinitski S. Factors influencing the regional deposition of inhaled particles in man. Clin Sci 1983;64:69-78.

11. International Labour Organization (ILO). International classification of radiographs of pneumoconioses. Geneva: ILO; 1980.

12. Cooper WC, Sargent EN. Study of chest radiographs and pulmonary functions in perlite workers. J Occup Med 1986; 28:199-206.

13. Crosbie WA. Respiratory health of carbon black workers. Arch Environ Health 1986;41:346-53.

14. Dick JA, Morgan WKC, Muir DFC, Reger RB, Sargent N. The significance of irregular opacities on the chest roentgenogram. Chest 1992;102:251-60.

15. Irwig LM, Rocks P. Lung function and respiratory symptoms in silicotic and nonsilicotic gold miners. Am Rev Respir Dis 
1978;117:429-35.

16. International Labour Organization (ILO). ILO U/C International classification of radiographs of pneumoconioses 1971. Geneva: ILO; 1972.

17. Cowie RL, Mabena SK. Silicosis, chronic airflow limitation, and chronic bronchitis in South African gold miners. Am Rev Respir Dis 1991;143:80-4.

18. Swaen GMH, Meijers JMM. Lung cancer risk among workers with silicosis: potential confounding by smoking habits. Am J Ind Med 1987;12:223-5.

19. Swaen GMH, Passier PECA, van Attekum AMNG. Prevalence of silicosis in the Dutch fine-ceramic industry. Int Arch Occup Environ Health 1988;60:71-4.

20. Meijers JMM, Swaen GMH, van Vliet K, Borm PJA. Epidemiologic studies of inorganic dust-related lung diseases in The Netherlands. Exp Lung Res 1990;16:15-23.

21. Cherry NM, Burgess GL, Turner S, McDonald JC. Crystalline silica and risk of lung cancer in the potteries. Occup Environ Med 1998;55:779-85.

22. McDonald JC, Burgess GL, Turner S, Cherry NM. Cohort study of Staffordshire pottery workers (III) lung cancer, radiographic changes, silica exposure and smoking habit. Ann Occup Hyg 1997;41 Suppl 1:412-4.

23. Graham WGB, Ashikaga T, Hemenway D, Weaver S, O'Grady RV. Radiographic abnormalities in Vermont granite workers exposed to low levels of granite dust. Chest 1991; 100:1507-14.

24. Harber P, Dahlgren J, Bunn W, Lockey J, Chase G. Radiographic and spirometric findings in diatomaceous earth workers. J Occup Environ Med 1998;40:22-8.

25. Ng T-P, Tsin TW, O'Kelly FJ, Chan SL. A survey of the respiratory health of silica-exposed gemstone workers in Hong Kong. Am Rev Respir Dis 1987;135:1249-54.

26. Hessel PA, Sluis-Cremer GK, Lee SL. Distribution of silicotic collagenization in relation to smoking habits. Am Rev Respir Dis 1991;144:297-301.

27. Glover JR, Bevan C, Cotes JE, Elwood PC, Hodges NG, Kell
RL, et al. Effects of exposure to slate dust in North Wales. Br J Ind Med 1980;37:152-62.

28. Ng T-P, Chan S-L. Lung function in relation to silicosis and silica exposure in granite workers. Eur Respir J 1992;5:98691.

29. Wang X, Yano E. Pulmonary dysfunction in silica-exposed workers: a relationship to radiographic signs of silicosis and emphysema. Am J Ind Med 1999;36:299-306.

30. Finkelstein MM. Silicosis surveillance in Ontario from 1979 to 1992. Scand J Work Environ Health 1995;21 Suppl 2:55-7.

31. Gardner LU, Middleton EL, Orenstein AI. Report upon medical aspects of silicosis, including etiology, pathology, and diagnostics: resolution adopted by the international conference held in at Johannesburg, South Africa, Aug, 1930: p 12-27.

32. Cavariani F, Di Pietro A, Miceli M, Forastiere F, Biggeri A, Scavalli P, et al. Incidence of silicosis among ceramic workers in central Italy. Scand J Work Environ Health 1995;21 Suppl 2:58-62.

33. Hnizdo E, Sluis-Cremer GK. Effect of tobacco smoking on the presence of asbestosis at postmortem and on the reading or irregular opacities on roentgenograms in asbestos-exposed workers. Am Rev Respir Dis 1988;138:1207-12.

34. Thurlbeck WM, Churg AM. Pathology of the Lung. New York: Theime; 1995. p 612-5.

35. Remy-Jardin M, Remy J, Boulenguez C, Sobaszek A, Edme J-L, Furon D. Morphologic effects of cigarette smoking on airways and pulmonary parenchyma in healthy adult volunteers: CT evaluation and correlation with pulmonary function tests. Radiology 1993;186:107-15.

36. Finkelstein MM. Radiographic silicosis and lung cancer risk among workers in Ontario. Am J Ind Med 1998;34:244-51.

37. Finkelstein MM. Radiographic abnormalities and the risk of lung cancer among workers exposed to silica dust in Ontario. Can Med Assoc J 1995;152:37-43.

Reveived for publication: 3 September 2002 